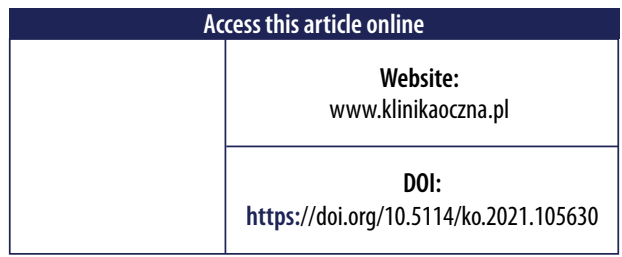

\title{
Uveal melanoma among octogenarians
}

\section{Marta Wróblewska-Zierhoffer' ${ }^{1}$, Wojciech Adamski', Anna Kubiak² ${ }^{2}$ Maciej Trojanowski², Jarosław Kocięcki ${ }^{1}$, Iwona Rospond-Kubiak'}

'Department of Ophthalmology, Poznan University of Medical Sciences, Poznan, Poland

${ }^{2}$ Greater Poland Cancer Registry, Greater Poland Cancer Centre, Poznan, Poland

\section{ABSTRACT}

Aim of the study: To investigate the natural course of the uveal melanoma among octogenarians registered in single centre database.

Material and methods: The data of the patients treated for uveal melanoma at the Department of Ophthalmology, Poznan University of Medical Sciences, Poland between 1991-2017 have been retrospectively reviewed. The survival data were obtained from the Greater Poland Cancer Registry. Patients were included in the study if they were 80 years old or more at time of the onset, they were excluded if there was no confirmed follow-up.

Results: Among 668 uveal melanoma patients registered in our database to 2017,47 patients were 80 years old or more at the time of treatment: 19 men, 28 women, mean age 83,62 years (range: 80-93). 8 tumours were T1(17\%), 12 - T2 (26\%), 16 - T3 (34\%), and $11-\mathrm{T} 4$ (23\%). 33 (70\%) tumours were managed by enucleation, $13(28 \%)$ by ruthenium brachytherapy, 1 (2\%) tumour was resected. With regards to irradiated patients we observed 1 recurrence 2 years after treatment. Median follow-up was 21 months (range: 2 to 104 months). 31 patients (66\%) died by the study close, 17 (55\%) of metastatic disease from uveal melanoma. Median time to metastatic death from uveal melanoma was 24 months. Conclusions: Metastatic death from uveal melanoma in this particular group of patients was related to tumour size at the onset and epithelioid type of melanoma.

KEY WORDS: survival, uveal melanoma, malignant neoplasm, eye.

\section{INTRODUCTION}

Uveal melanoma is the most common primary intraocular malignancy in adults and accounts for approximately 85$90 \%$ of all uveal melanoma cases. Its incidence is estimated to be around 6-7 cases per million Caucasians, with no major difference between the sexes. According to some recent reports, it tends to be more common in Scandinavians, even up to 8 cases per million [1].

Choroidal melanoma is typically diagnosed in the $6-7^{\text {th }}$ decade of life with the average age at the time of diagnosis of approximately 62 years. Symptoms of the disease may include - significant deterioration of visual acuity, photopsias, metamorphopsias, scotomas or painful eye. Of note, even up to $30 \%$ of cases can be asymptomatic at presentation, with accidental detection during routine fundus examination $[4,5]$.

Despite the improvements in local treatment, according to literature, approximately $50 \%$ of patients would develop metastatic disease within 5 years from the diagnosis. The most common localization of metastases is the liver $[2-5,14$, 16]. The prognosis for survival depends on various factors, including tumour size and location, the presence of epithelioid cells and genetic markers i.e. chromosome 3 loss, 8q gain,
$1 \mathrm{p}$ and $6 \mathrm{q}$ loss - those being associated with rather poor prognosis. Moreover, according to available literature, prognosis for survival deteriorates significantly with age $[3,4,12,14,16]$.

As the European societies are ageing, more seniors are being now diagnosed with various ocular conditions including uveal melanoma. There is little data in the literature regarding the course of this tumour in a group of patients over 80 years of age. Little data is also found on the survival rate of uveal melanoma patients in Eastern Europe [6], although the incidence data are partially available [13].

\section{AIM OF THE STUDY}

The purpose of the study was to investigate the course of uveal melanoma in terms of patients' survival and treatment results among the octogenarians in single centre database from Department of Ophthalmology, Poznan University of Medical Sciences.

\section{MATERIAL AND METHODS}

Retrospective data review covered medical records of patients treated for choroidal melanoma at the Department of Ophthalmology, Poznan University of Medical Sciences, 
between 1991 and 2017. Patients were included in the study if they were at the age over 80 years at the time of onset and the time of follow-up was well documented.

The diagnosis of choroidal melanoma was based on ophthalmic examination, which included: clinical assessment, fundus examination and B-scan ultrasound. In some cases autofluorescence or other contrast examinations were also performed. Prior to the surgical treatment, staging (according to the TNM $8^{\text {th }}$ edition) and general tests for distant metastases (chest X-rays and abdominal ultrasound) were also performed. For enucleated globes standard histopathological assessment was done. Since 2013, all enucleations were followed with orbital implant placement. The decision as to the treatment method were made after the assessment of tumour location (the proximity to the optic disc), patient general condition and also his/her preferences. All patients eligible for the treatment the options not available at our centre (proton beam radiotherapy/iodine brachytherapy) were referred for further treatment elsewhere, if applicable.

The follow-up visits following the treatment were planned according to the scheme - 1 week postop, then 1 month after treatment, 3 months, 9 months and afterwards annually with some modifications, if necessary. Each follow-up visit included slit lamp examination, palpation of the orbit if applicable, fundus ophthalmoscopy, B-scan ultrasonography with assessment of tumour dimensions, OCT scan (since 2006) and fundus photography (colour and autofluorescence since 2008). Additionally, every 6 months abdominal ultrasonography was performed for metastases screening.

All data regarding causes and dates of deaths came from Greater Poland Cancer Registry operating at Greater Poland Cancer Centre, Poznan. The study adhered to the tenets of the declaration of Helsinki and as an institutional audit review required no bioethical approval.

For the statistical analysis Statistica 13.1 software was used. In the case of quantitative variables (tumor thickness

\section{Table I. Patients' characteristics}

\begin{tabular}{|l|c|}
\hline Sex & 19 \\
\hline Men & 28 \\
\hline Women & 83.62 \\
\hline Mean & 80 \\
\hline Min & 93 \\
\hline Max & \\
\hline Treatment & 33 \\
\hline Enucleation & 13 \\
\hline Ru-106 brachytherapy & 1 \\
\hline Resection & \\
\hline Follow-up (months) & 26.0 \\
\hline Mean & 21.0 \\
\hline Median & \\
\hline
\end{tabular}

and largest basal diameter), a comparison of the observed distribution with the normal distribution was performed (Shapiro-Wilk test). Due to the fact that the distribution of variables was not consistent with the normal distribution, the non-parametric Mann-Whitney test was used to check if there were statistically significant differences between the groups. For qualitative variables (TNM, stage, histopathological variant), the $\chi^{2}$ test or Fisher's exact test was used. The significance level was assumed to be lower than 0.05 .

\section{RESULTS}

Among 668 uveal melanoma patients registered in Poznan database, 47 (7\%) were 80 years old or more at the time of treatment and therefore could be included in the study. This group comprised 19 men, 28 women in the mean age of 83.62 years (range: $80-93) .8$ tumours were T1 (17\%), 12 - T2 (26\%), 16 - T3 (34\%), and $11-\mathrm{T} 4$ (23\%) (TNM $8^{\text {th }}$ edition). Clinical stage (staging) was also assessed - 7 tumours were at stage I (15\%), 13 - IIA (28\%), 13 - IIB (28\%), 11 - IIIA (23\%), and 3 - IIIB (6\%) (Tables I, II).

$33(70 \%)$ tumours were managed by enucleation, 13 (28\%) by ruthenium brachytherapy, $1(2 \%)$ anterior tumour was managed by trans-scleral local resection with subsequent irradiation of the tumour bed due to small tumour base and

Table II. Size and staging of treated melanomas Tumours largest basal diameter $(\mathrm{mm})$

\begin{tabular}{|c|c|c|}
\hline Mean & \multicolumn{2}{|c|}{12.78} \\
\hline Min & \multicolumn{2}{|c|}{5.89} \\
\hline Max & \multicolumn{2}{|c|}{23.00} \\
\hline \multicolumn{3}{|c|}{ Tumours height (mm) } \\
\hline Mean & \multicolumn{2}{|c|}{8.51} \\
\hline Min & \multicolumn{2}{|c|}{1.87} \\
\hline Max & \multicolumn{2}{|c|}{20.00} \\
\hline \multicolumn{3}{|c|}{ Histological type } \\
\hline Epithelial cell & \multicolumn{2}{|c|}{4} \\
\hline Spindle cell & \multicolumn{2}{|c|}{14} \\
\hline Mixed cell & \multicolumn{2}{|c|}{16} \\
\hline TNM $\left(8^{\text {th }} \mathrm{ed}\right)$ & No. of patients & $\%$ of patients \\
\hline $\mathrm{T} 1$ & 8 & $17 \%$ \\
\hline $\mathrm{T} 2$ & 12 & $26 \%$ \\
\hline $\mathrm{T} 3$ & 16 & $34 \%$ \\
\hline T4 & 11 & $23 \%$ \\
\hline Stage $\left(8^{\text {th }} \mathrm{ed}\right)$ & No. of patients & $\%$ of patients \\
\hline I & 7 & $15 \%$ \\
\hline$\| A$ & 13 & $28 \%$ \\
\hline IIB & 13 & $28 \%$ \\
\hline IIIA & 11 & $23 \%$ \\
\hline IIIB & 3 & $6 \%$ \\
\hline
\end{tabular}


the patient' wish to preserve the eye. Histopathological results presented 4 (12\%) epithelioid melanomas, 14 (41\%) spindle cell and $16(47 \%)$ of mixed cell type. We noted no orbital recurrence and with regards to irradiated patients we noted 1 recurrence, 2 years after primary treatment managed with secondary enucleation.

Median documented follow-up was 21 months (range: 2 to 104 months), however 31 patients $(66 \%)$ died by the study close, 17 of them (55\%) of metastatic disease from uveal melanoma, 14 (45\%) of unrelated causes, of which 1 patient (2\%) died due to concomitant cancer. Median time to metastatic death from uveal melanoma was 24 months (Table III).

The metastatic death was related to: tumour size at presentation, i.e largest basal diameter $(p=0.001)$, tumour thickness $(p=0.003)$, TNM $(p<0.001)$, stage $(p<0.001)$ and histopathological type of tumour $(p=0.005)$. We compared also the group of surviving patients with the those who died out of metastases and other causes and found out that the tumours in the metastatic group were bigger $(p=0.004$ and 0.001$)$ and more commonly of epithelioid type ( $p=0.028$; Tables IV, V).

\section{DISCUSSION}

The study on this small group of patients shows that choroidal melanoma is a rare condition in patients over 80 years of age (only $7 \%$ of all patients registered in our database). This does not represent the data of the whole Polish population. In the other report concerning the incidence of uveal melanoma in Poland, the number of patients older than 80 years was even lower [13].

Choroidal melanoma occurs at the constant frequency with a peak of incidence in 6-7 decade of life. Due to better treatment availability and improving standard of living, seniors' lifespan is getting longer. Therefore the dilemma as to the choice of treatment method in patients over 80 years of age will probably concern an increasing number of patients.

There is little data in the literature regarding the course of melanoma in a group of patients over 80 years of age. The available research from Finnish scientists proves that in this group of patients metastatic disease is not a leading cause of death, giving way to other diseases typical for older age [7]. The explanation for this fact could be that it always takes a certain time for the metastases to grow and the older patients may not live long enough for them to form.

An interesting suggestion is the fact that worse prognosis with age might simply mean that the tumor managed to grow unnoticed for a longer time and that the cancer cells had the opportunity to circulate longer in the bloodstream and therefore could have undergone more cell divisions towards greater aggressiveness [15]. In a large study presenting such a thesis, Damato et al. [16], based on an analysis of a group of 3072

Table III. Analysis of deaths in follow-up period

\begin{tabular}{|l|c|c|c|c|c|c|}
\hline & \multicolumn{2}{|c|}{ All cases } & \multicolumn{2}{c|}{ Metastatic disease } & \multicolumn{2}{c|}{ Unrelated causes } \\
\hline Death (No. of patients / \% of patients) & \multicolumn{2}{|c|}{$31 / 66 \%$} & \multicolumn{2}{|c|}{$17 / 55 \%$} & \multicolumn{2}{c|}{$1445 \%$} \\
\hline & Mean & Median & Mean & Median & Mean & Median \\
\hline Time to death after treatment (months) & 49.6 & 39 & 29.9 & 24 & 73.6 & 81.5 \\
\hline
\end{tabular}

Table IV. Patients' ${ }^{\prime}$ characteristics - subgroup analysis

\begin{tabular}{|c|c|c|c|c|}
\hline & $\begin{array}{c}\text { Total } \\
(n=47)\end{array}$ & $\begin{array}{l}\text { Still alive } \\
(n=16)\end{array}$ & $\begin{array}{l}\text { Death due to metastatic disease } \\
\qquad(n=17)\end{array}$ & $\begin{array}{l}\text { Death due to unrelated causes } \\
\qquad(n=14)\end{array}$ \\
\hline \multicolumn{5}{|l|}{ Sex } \\
\hline Men & 19 & 5 & 8 & 6 \\
\hline Women & 28 & 11 & 9 & 8 \\
\hline \multicolumn{5}{|l|}{ Age } \\
\hline Mean & 83.62 & 83.6 & 83.8 & 83.5 \\
\hline Min & 80 & 80 & 80 & 80 \\
\hline Max & 93 & 89 & 93 & 92 \\
\hline \multicolumn{5}{|c|}{ Treatment (No. of patients / \% of patients) } \\
\hline Enucleation & $33 / 70 \%$ & $9 / 56 \%$ & $14 / 82 \%$ & $10 / 71 \%$ \\
\hline Ru-106 brachytherapy & $13 / 28 \%$ & $6 / 38 \%$ & $3 / 18 \%$ & $4 / 29 \%$ \\
\hline Resection & $1 / 2 \%$ & $1 / 6 \%$ & 0 & 0 \\
\hline \multicolumn{5}{|l|}{ Follow-up (months) } \\
\hline Mean & 26.0 & 29.3 & 20.1 & 29.3 \\
\hline Median & 21.0 & 24 & 17 & 22.5 \\
\hline
\end{tabular}


Table V. Size and staging of treated melanomas - subgroups analysis

\begin{tabular}{|c|c|c|c|c|c|}
\hline & $\begin{array}{c}\text { Total } \\
(n=47)\end{array}$ & $\begin{array}{l}\text { Still alive } \\
(n=16)\end{array}$ & $\begin{array}{l}\text { Death due to metastatic } \\
\text { disease }(n=17)\end{array}$ & $\begin{array}{l}\text { Death due to unrelated } \\
\text { causes }(n=14)\end{array}$ & $p$-value \\
\hline \multicolumn{6}{|c|}{ Tumours largest basal diameter (mm) } \\
\hline Mean & 12.78 & 11.57 & 15.54 & 10.80 & \multirow{3}{*}{$(p=0.001)$} \\
\hline Min & 5.89 & 5.89 & 10.12 & 7.00 & \\
\hline Max & 23.00 & 19.00 & 23.00 & 20.00 & \\
\hline \multicolumn{6}{|c|}{ Tumours height (mm) } \\
\hline Mean & 8.51 & 6.57 & 11.77 & 6.78 & \multirow{3}{*}{$(p=0.003)$} \\
\hline Min & 1.87 & 1.87 & 5.20 & 2.20 & \\
\hline Max & 20.0 & 12.83 & 20.00 & 12.40 & \\
\hline \multicolumn{6}{|c|}{ Histological type } \\
\hline Epithelial cell & 4 & 0 & 3 & 1 & \multirow{3}{*}{$(p=0.028)$} \\
\hline Spindle cell & 14 & 8 & 2 & 4 & \\
\hline Mixed cell & 16 & 2 & 9 & 5 & \\
\hline \multicolumn{6}{|c|}{ TNM ( $8^{\text {th }}$ ed.) (No. of patients / $\%$ of patients) } \\
\hline $\mathrm{T} 1$ & $8 / 17 \%$ & $5 / 31 \%$ & 0 & $3 / 21 \%$ & \multirow{4}{*}{$(p=0.04)$} \\
\hline $\mathrm{T} 2$ & $12 / 26 \%$ & $3 / 19 \%$ & $3 / 18 \%$ & $6 / 43 \%$ & \\
\hline $\mathrm{T} 3$ & $16 / 34 \%$ & $7 / 44 \%$ & $6 / 35 \%$ & $3 / 21 \%$ & \\
\hline $\mathrm{T} 4$ & $11 / 23 \%$ & $1 / 6 \%$ & $8 / 47 \%$ & $2 / 14 \%$ & \\
\hline \multicolumn{6}{|c|}{ Stage ( $8^{\text {th }}$ ed.) (No. of patients / $\%$ of patients) } \\
\hline I & $7 / 15 \%$ & $5 / 31 \%$ & 0 & $2 / 14 \%$ & \multirow{5}{*}{$(p=0.082)$} \\
\hline$\| A$ & $13 / 28 \%$ & $3 / 19 \%$ & $3 / 18 \%$ & $7 / 50 \%$ & \\
\hline$\| B$ & $13 / 28 \%$ & $5 / 31 \%$ & $6 / 35 \%$ & $2 / 14 \%$ & \\
\hline IIIA & $11 / 23 \%$ & $2 / 13 \%$ & $7 / 41 \%$ & $2 / 14 \%$ & \\
\hline IIIB & $3 / 6 \%$ & $1 / 6 \%$ & $1 / 6 \%$ & $1 / 7 \%$ & \\
\hline
\end{tabular}

patients over 19 years, noticed that in older patients the tumors were larger, and often had a greater degree of histological malignancy associated with chromosomal abnormalities.

Al-Jamal et al. proved on basis of an analysis of melanoma course in patients under 25 years of age that there might be 2 periods in human life, where the biology of choroidal melanoma changes significantly, namely around age of 11 and 40 years [8]. Choroidal melanoma in patients under 20 years of age is a rare condition, which usually occurs during or shortly after puberty period. Analysis of a large group of patients proved that if the tumour occurred before the age of 11 , the risk of metastases is low. [8]. The course of choroidal melanoma in younger patients might be related to occurring hormonal changes, the next part of which takes place around 36-40 years of age. Perhaps the way the immune sys- tem works, which "diminishes with age", can also have some significance for the onset of the disease. This could explain the higher incidence of choroidal melanoma in 6-7 decade of life. All of the above facts might slightly change the view of the occurrence of choroidal melanoma with age, but these are only hypotheses [8-11].

\section{CONCLUSIONS}

Uveal melanoma among octogenarians is rare. The metastatic spread in this age group was related to the size of the tumour at the onset, TNM staging and the presence of epithelioid cells.

\section{DISCLOSURE}

The authors declare no conflict of interest. 


\section{REFERENCES}

1. Virgili G, Gatta G, Ciccolallo L, et al. Incidence of uveal melanoma in Europe. Ophthalmology 2007; 114: 2309-2315.

2. Krantz BA, Dave N, Komatsubara KM, et al. Uveal melanoma: epidemiology, etiology, and treatment of primary disease. Clinical Ophthalmology (Auckland, NZ) 2017; 11: 279-289.

3. Kaliki S, Shields CL, Shields JA. Uveal melanoma: Estimating prognosis. Indian Journal of Ophthalmology 2015; 63: 93-102.

4. Damato B. Progress in the management of patients with uveal melanoma: the 2012 Ashton Lecture. Eye (Lond) 2012; 26: 11571172.

5. Kujala E, Makitie T, Kivela T. Very long-term prognosis of patients with malignant uveal melanoma. Invest Ophthalmol Vis Sci 2003; 44: 4651-4659.

6. Virgili G, Gatta G, Ciccolallo L, et al. Survival in patients with uveal melanoma in Europe. Arch. Ophthalmol 2008; 126: 1413-1418.

7. Al-Jamal R, Kivelä T. Uveal melanoma among Finnish octogenarians. Acta Ophthalmologica 2013; 91: 252.

8. Al-Jamal RT, Cassoux N, Desjardins L, et al. The Pediatric Choroidal and Ciliary Body Melanoma Study: A Survey by the European Ophthalmic Oncology Group. Ophthalmology 2016; 123: 898-907.

9. Singh AD, Shields CL, Shields JA, Sato T. Uveal melanoma in young patients. Arch Ophthalmol 2000; 118: 918-923.

10. Shields CL, Kaliki S, Arepalli S, et al. Uveal melanoma in children and teenagers. Saudi Journal of Ophthalmology 2013; 27: 197-201.

11. Al-Jamal R, Kivelä T. Uveal melanoma among Finnish children and young adults. J AAPOS 2014; 18: 61-66.

12. Shields CL, Furuta M, Thangappan A, et al. Metastasis of Uveal Melanoma Millimeter-by-Millimeter in 8033 Consecutive Eyes. Arch Ophthalmol 2009; 127: 989-998.

13. Pogrzebielski A, Romanowska-Dixon B, Starzycka M, et al. Epidemiology of choroidal melanoma in the material of the Department of Ophthalmology CM UJ in Cracow. Klin 0czna 2004; 106 (3 Suppl): 445-447.

14. Jager MJ, Shields CL, Cebulla CM, et al. Uveal melanoma. Nat Rev Dis Primers 2020; 6: 24

15. Damato B. Ocular treatment of choroidal melanoma in relation to the prevention of metastatic death - A personal view. Prog Retin Eye Res 2018; 66: 187-199.

16. Damato BE, Heimann H, Kalirai H, et al. Age, Survival Predictors, and Metastatic Death in Patients With Choroidal Melanoma: Tentative Evidence of a Therapeutic Effect on Survival. JAMA Ophthalmol 2014; 132: 605. 